Article

\title{
Electrothermally-Actuated Micromirrors with Bimorph Actuators-Bending-Type and Torsion-Type
}

\author{
Cheng-Hua Tsai ${ }^{\dagger}$, Chun-Wei Tsai ${ }^{\dagger}$, Hsu-Tang Chang, Shih-Hsiang Liu and Jui-Che Tsai * \\ Graduate Institute of Photonics and Optoelectronics and the Department of Electrical Engineering, \\ National Taiwan University, Taipei 10617, Taiwan; E-Mails: chenghua.tsai@gmail.com (C.-H.T.); \\ d98941019@ntu.edu.tw (C.-W.T.); ckjamesbond@gmail.com (H.-T.C.); \\ r01941068@ntu.edu.tw (S.-H.L.)
}

$\dagger$ These authors contributed equally to this work.

* Author to whom correspondence should be addressed; E-Mail: juichetsai@ntu.edu.tw; Tel.: +886-2-3366-3686.

Academic Editor: Stefano Mariani

Received: 31 March 2015 / Accepted: 13 May 2015 / Published: 22 June 2015

\begin{abstract}
Three different electrothermally-actuated MEMS micromirrors with $\mathrm{Cr} / \mathrm{Au}-\mathrm{Si}$ bimorph actuators are proposed. The devices are fabricated with the SOIMUMPs process developed by MEMSCAP, Inc. (Durham, NC, USA). A silicon-on-insulator MEMS process has been employed for the fabrication of these micromirrors. Electrothermal actuation has achieved a large angular movement in the micromirrors. Application of an external electric current $0.04 \mathrm{~A}$ to the bending-type, restricted-torsion-type, and free-torsion-type mirrors achieved rotation angles of $1.69^{\circ}, 3.28^{\circ}$, and $3.64^{\circ}$, respectively.
\end{abstract}

Keywords: microelectromechanical devices; electrothermal effects; silicon on insulator

\section{Introduction}

Micro-electro-mechanical systems (MEMS)-based micromirrors are widely used for various applications, including optical communication [1], optical switches [2], optical displays [3], biomedical imaging [4,5], and optical interconnects [6]. Proposed driving mechanisms for MEMS mirrors include electrostatic, magnetic, piezoelectric, and thermal actuation. The major advantage of electrostatic actuation is the simple capacitor-like structures [7-9]. However, a high driving voltage is generally 
required. Magnetic actuation usually causes a large linear or angular displacement. There are two common approaches to implement magnetic actuation. One is to utilize the Lorentz force [10]; this requires feeding an electric current into the device, resulting in constant power dissipation due to ohmic heating. The other is to make the entire or part of the device out of a magnetic material, and use an external magnet to actuate the device [11,12]. Regarding piezoelectric actuation [13], piezoelectric materials are relatively less common in semiconductor processes. Thermal actuation can generally achieve relatively large displacement and rotation. The structures can be heated by applying a current. Although thermal actuation normally requires constant power dissipation and may be unable to operate at very high frequencies, its large rotation angle with low driving voltage make it ideal for other applications [14-18]. This study will compare mirrors with different thermal bimorph actuators. A bimorph actuator deforms when being heated due to the mismatch in the coefficients of thermal expansion (CTE) [19-22].

Thanks to its process maturity, SOI processes are commonly used to fabricate electrothermal actuators [23]. Particularly, several electrothermal actuators manufactured with standard foundry SOI processes such as the SOIMUMPs process (MEMSCAP Inc., Durham, NC, USA) were reported [24-26].

Generally, in an electrothermally actuated tilting mirror, the bimorph structures serve as the bending flexures [27]. However, it is more straightforward to accomplish mirror tilt using torsion motion because the rotation axis can be easily defined. Therefore, in this paper, we present three different MEMS mirrors that can be electrothermally-actuated; in addition to a bending-type mirror, we also demonstrate mirrors in which the bimorph structures serve as the torsion beams. All the devices are fabricated with the SOIMUMPs process. There is a great potential for mass production and monolithic integration with other MEMS components.

\section{Design and Fabrication}

Figure 1 shows the 3-D schematic drawings of the electrothermally-actuated MEMS mirrors. Three different devices were designed: 'bending-type mirror' (Figure 1a), 'restricted-torsion-type mirror' (Figure 1b), and 'free-torsion-type mirror' (Figure 1c). The 'bending-type' mirror has two bimorph actuators on the upper left and lower left; the left side of the mirror connects through seven bending beams with the Si substrate. The widths of the bimorph actuator and the bending beam are 10 and $4 \mu \mathrm{m}$, respectively. The bimorph actuator and bending beam are both $150 \mu \mathrm{m}$ long. The resonance frequency of the 'bending-type' mirror is estimated as $28,597 \mathrm{~Hz}$. As for the 'restricted-torsion-type' mirror, its one end is connected to a torsion spring, and the other end is restricted by some springs. The length and width of the torsion spring are 925 and $16 \mu \mathrm{m}$, respectively. The resonance frequency of each type of mirror is calculated. It can be observed that in addition to the two bimorph actuators, the bending-type mirror has seven additional bending beams connecting to the anchor, so it is expected to have higher resonance frequency than the others. Ignoring the restricting springs, the resonance frequency of the 'restricted-torsion-type' mirror is estimated as $835.6 \mathrm{~Hz}$. In a 'free-torsion-type' mirror, only one end of mirror is connected to a torsion spring. The length and width of the torsion spring are 925 and $16 \mu \mathrm{m}$, respectively. The resonance frequency of the 'free-torsion-type' mirror is estimated as $848.7 \mathrm{~Hz}$. The overhead views of the three bimorph actuator designs show that the $\mathrm{Cr} / \mathrm{Au}-\mathrm{Si}$ bimorph structures overlap with a through-silicon hole below them. Table 1 shows the dimensions and parameters of the 
three proposed mirror designs. The mass of the three mirrors, including frame and the metal coating, is $2.37 \times 10^{-5}, 3.31 \times 10^{-5}$, and $3.24 \times 10^{-5} \mathrm{~g}$, respectively. The resonance frequencies are estimated values for devices without metal. Besides, the radius of curvature $(\mathrm{R})$ of the fabricated mirror with metal coating is measured to be $\sim 20 \mathrm{~mm}$.
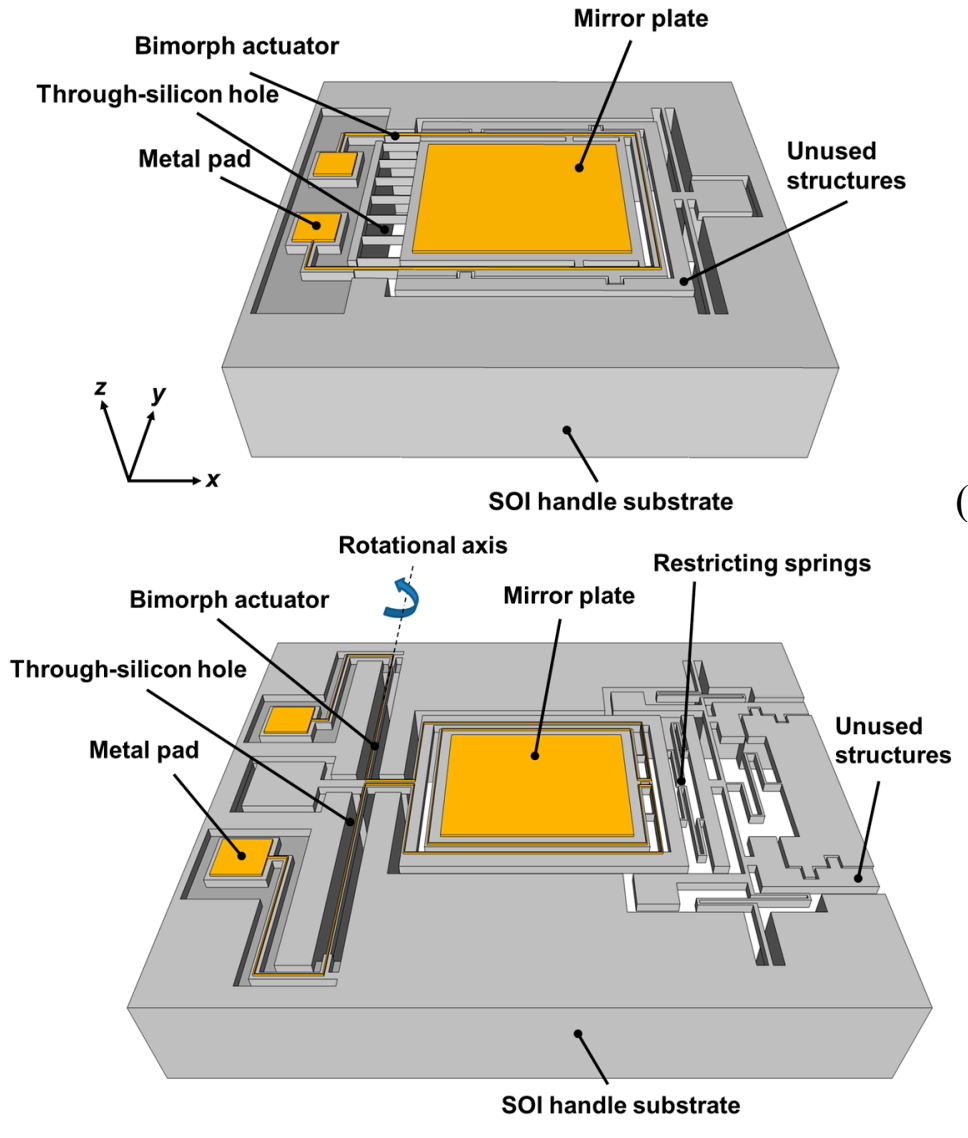

(a)

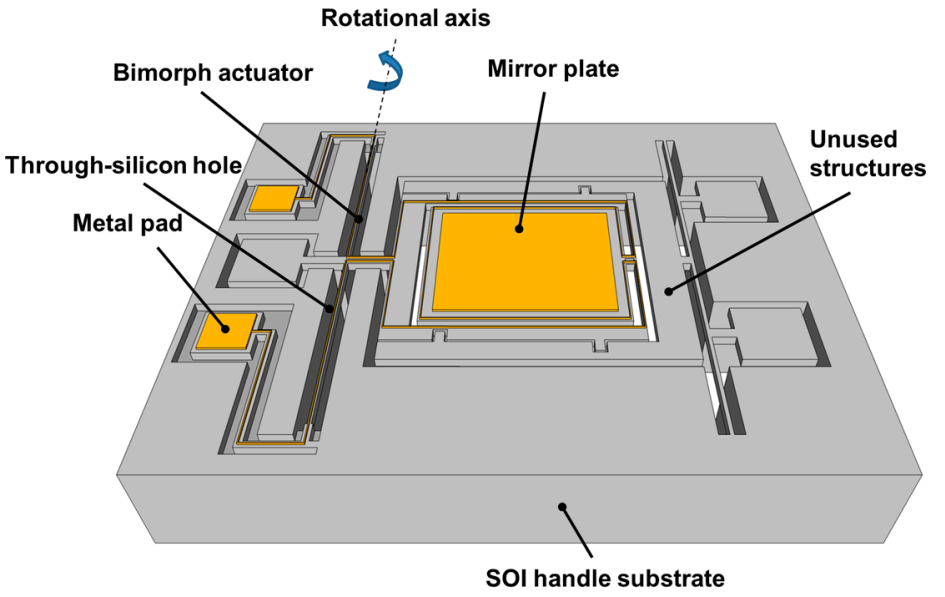

(b)

(c)

Figure 1. The 3-D schematic drawings of the (a) bending-type, (b) restricted-torsion-type and (c) free-torsion-type electrothermally-actuated micro-electro-mechanical systems (MEMS) mirrors. For simplicity, buried oxide is not shown. 
Table 1. Dimensions/parameters for three micromirror designs.

\begin{tabular}{lcccc}
\hline Material & Bending-Type & Restricted-Torsion-Type & Free-Torsion-Type & Unit \\
\hline Overall footprint & $1.85 \times 1.73$ & $2.68 \times 2.36$ & $2.81 \times 2.36$ & $\mathrm{~mm}^{2}$ \\
Mirror plate & $0.91 \times 0.91$ & $1.13 \times 1.02$ & $1.10 \times 1.02$ & $\mathrm{~mm}^{2}$ \\
Gold-coated area & $760 \times 670$ & $780 \times 680$ & $780 \times 680$ & $\mu \mathrm{m}^{2}$ \\
Thicknesses of the silicon device & 10,400 & 10,400 & 10,400 & $\mu \mathrm{m}$ \\
layer and the handle substrate & 150,10 & 925,16 & 925,16 & $\mu \mathrm{m}$ \\
Bimorph actuator length and width & $2.37 \times 10^{-5}$ & $3.31 \times 10^{-5}$ & $3.24 \times 10^{-5}$ & $\mathrm{~g}$ \\
$\begin{array}{l}\text { Mass of the mirror including frame } \\
\text { and the metal coating }\end{array}$ & 28597 & 835.6 & 848.7 & $\mathrm{~Hz}$ \\
Resonance frequency & & & & \\
\hline
\end{tabular}

Each device consists of a gold-coated mirror area, metal pads for landing the probes, and bimorph actuators. The bimorph actuator consists of a two-layer structure in which each layer has different thermal expansion coefficients; A Cr/Au electrically conducting layer is on top of the Si beam suspended over a through-silicon hole. In the torsion-type mirrors, the bimorph beam is also the torsion spring of the mirror plate. Thermal stress causes the torsion spring to deform. Table 2 shows the material properties of the bimorph actuators.

Table 2. Material properties of the bimorph actuator.

\begin{tabular}{ccccc}
\hline Material & Silicon [28,29] & Cr [29] & Au [29] & Unit \\
\hline Coefficient of thermal expansion (CTE) $\alpha$ & 2.6 & 4.9 & 14.2 & $10^{-6} /{ }^{\circ} \mathrm{C}$ \\
Young's modulus $E$ & 160 & 279 & 79 & $\mathrm{GPa}$ \\
Thermal conductivity $K$ & 149 & 93.9 & 318 & $\mathrm{~W} /\left(\mathrm{m} \cdot{ }^{\circ} \mathrm{C}\right)$ \\
Mass Density $\rho$ & 2.33 & 7.14 & 19.3 & $\mathrm{~g} / \mathrm{cm}^{3}$ \\
Poisson's ratio $v$ & 0.28 & 0.21 & 0.44 & \\
\hline
\end{tabular}

The bimorph actuator is composed of a $\mathrm{Cr} / \mathrm{Au}$ top layer and $\mathrm{Si}$ bottom layer. Metal materials such as $\mathrm{Cr}$ and $\mathrm{Au}$ have a higher CTE compared to silicon. The deformation of the bimorph actuator during heating results from the CTE mismatch between layers. The devices are fabricated with the SOIMUMPs process developed by MEMSCAP, Inc. (Durham, NC, USA) [30], which uses silicon-on-insulator (SOI) wafers with a $10-\mu \mathrm{m}$ device layer, $1-\mu \mathrm{m}$ buried oxide, and $400-\mu \mathrm{m}$ handle substrate. In the region of the mirror plate, a metal layer of $50-\mathrm{nm} \mathrm{Cr}$ and $600-\mathrm{nm} \mathrm{Au}$ is coated on the top of the device layer to increase the optical reflectivity. At the end of the fabrication process, the mirror plate and bimorph actuators are released.

Figures $2 \mathrm{a}-\mathrm{c}$ are optical microscope images of the bending-type mirror, restricted-torsion-type mirror, and free-torsion-type mirror, respectively. Figure 3 is a schematic drawing of the device from a cross-sectional view along the $\mathrm{A}-\mathrm{A}^{\prime}$ shown in Figure 2c. The structure details are depicted and the materials used are shown. These mirrors are actuated by sending a current mainly through the $\mathrm{Cr} / \mathrm{Au}$ top layer. The temperature of the bimorph actuator is then substantially increased by Joule heating. The $\mathrm{Cr} / \mathrm{Au}$ top layer has a higher effective CTE compared to Si bottom layer, causing the top layer expands differently from the bottom layer. This further causes the mirror to tilt away from its initial posture. 

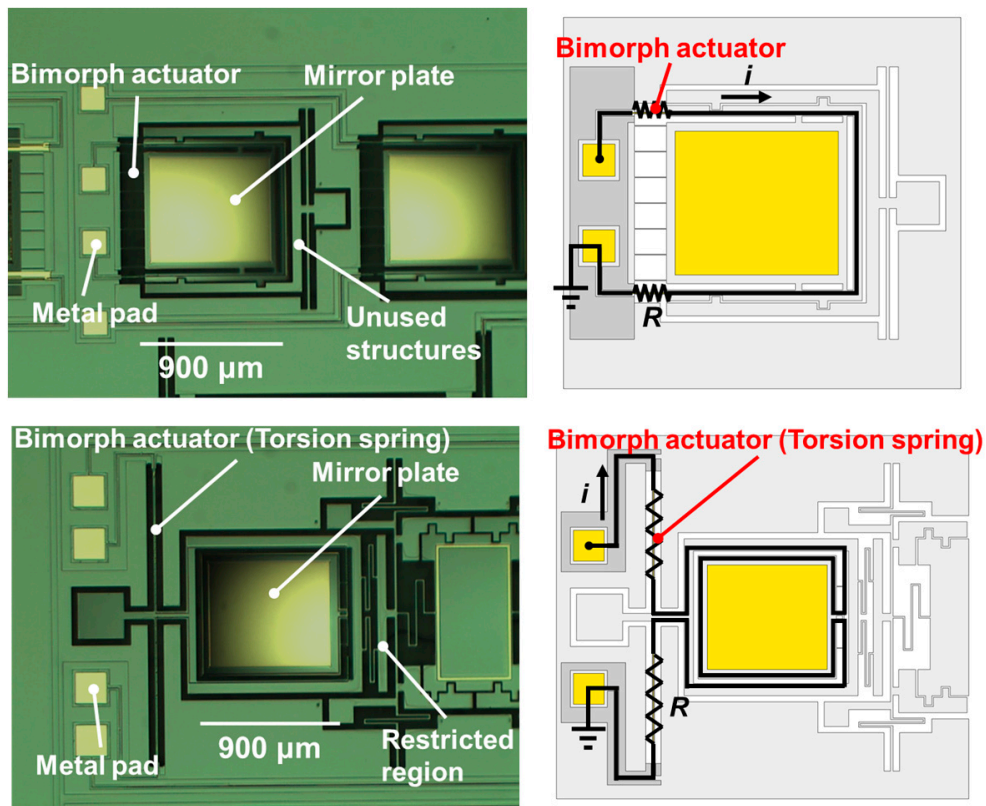

(a)
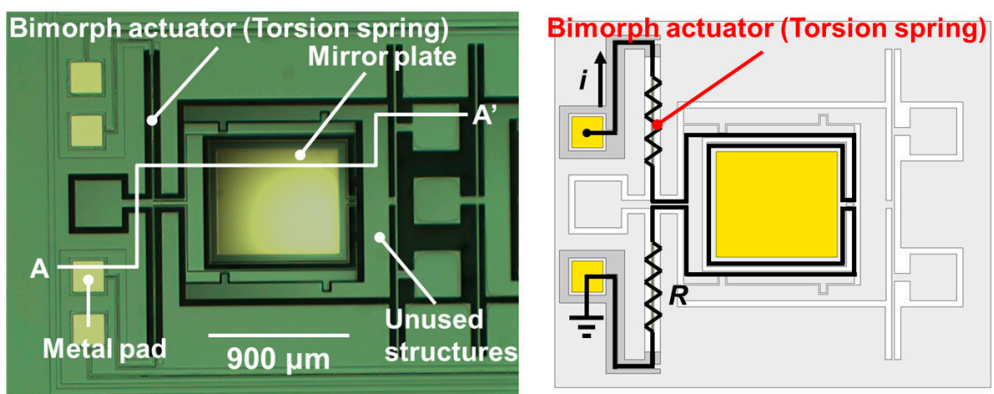

(b)

(c)

Figure 2. Photos of the three different electrothermally-actuated MEMS mirrors: (a) bending-type, (b) restricted-torsion-type, and (c) free-torsion-type.

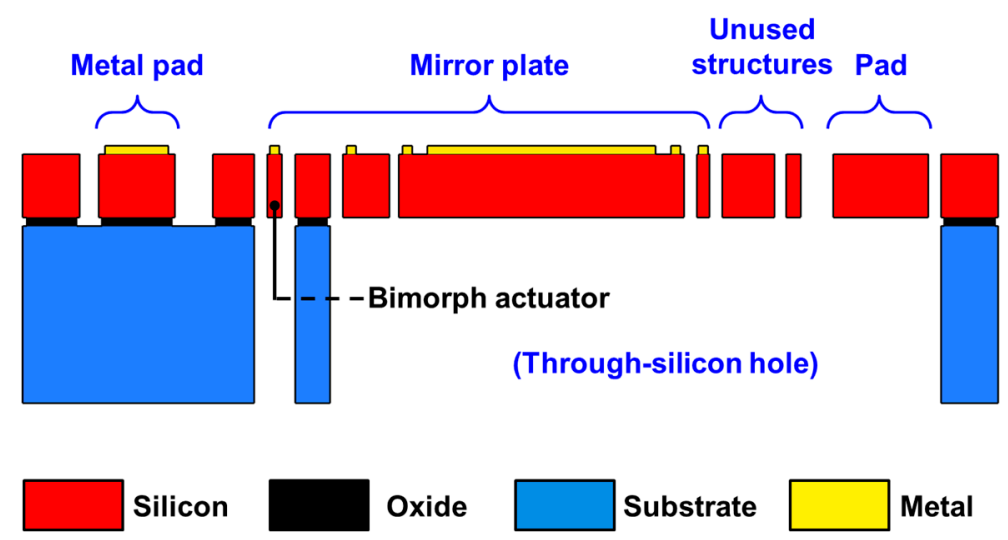

Figure 3. Schematic cross-section view along A-A' of Figure 2c. The structure details are depicted and the materials used are shown.

\section{Experimental Section}

Figure 4 shows the experimental setup used to determine how the applied electric current affects the rotation angle, where the microscope helps with observing the mirror motion. The power supply, current meter, probe and the device are connected in series. The initial pre-tilt angle relative to the substrate 
surface, if any, is defined as $\theta_{\mathrm{i}}$. The resolution is better than $0.02^{\circ}$. When applying the current, in the case where the mirror tilt angle relative to the substrate surface, $\theta$, is greater than the pre-tilt angle $\theta_{\mathrm{i}}$, the rotation angle $\Delta \theta\left(=\theta-\theta_{\mathrm{i}}\right)$ is positive. In contrast, if the mirror tilt angle relative to the substrate surface, $\theta$, is less than the initial pre-tilt angle, the rotation angle $\Delta \theta\left(=\theta-\theta_{\mathrm{i}}\right)$ is negative. For each design, we test two identical devices, but with different total electrical resistances due to their difference in total wire length; the theoretical resistance values are calculated to be approximately 65 and $150 \Omega$, respectively, ignoring the underlying silicon. Later in the paper, we will use ' $65 \Omega$ ' and ' $150 \Omega$ ' to denote the low-resistance and high-resistance devices in each design, respectively. During testing, the chip is mounted on a fixed holder. After applying an electric current to the device through the probes, the rotation angle, corresponding voltage and electrical resistance are measured. The bending-type, restricted-torsion-type, and free-torsion-type mirrors are then compared.

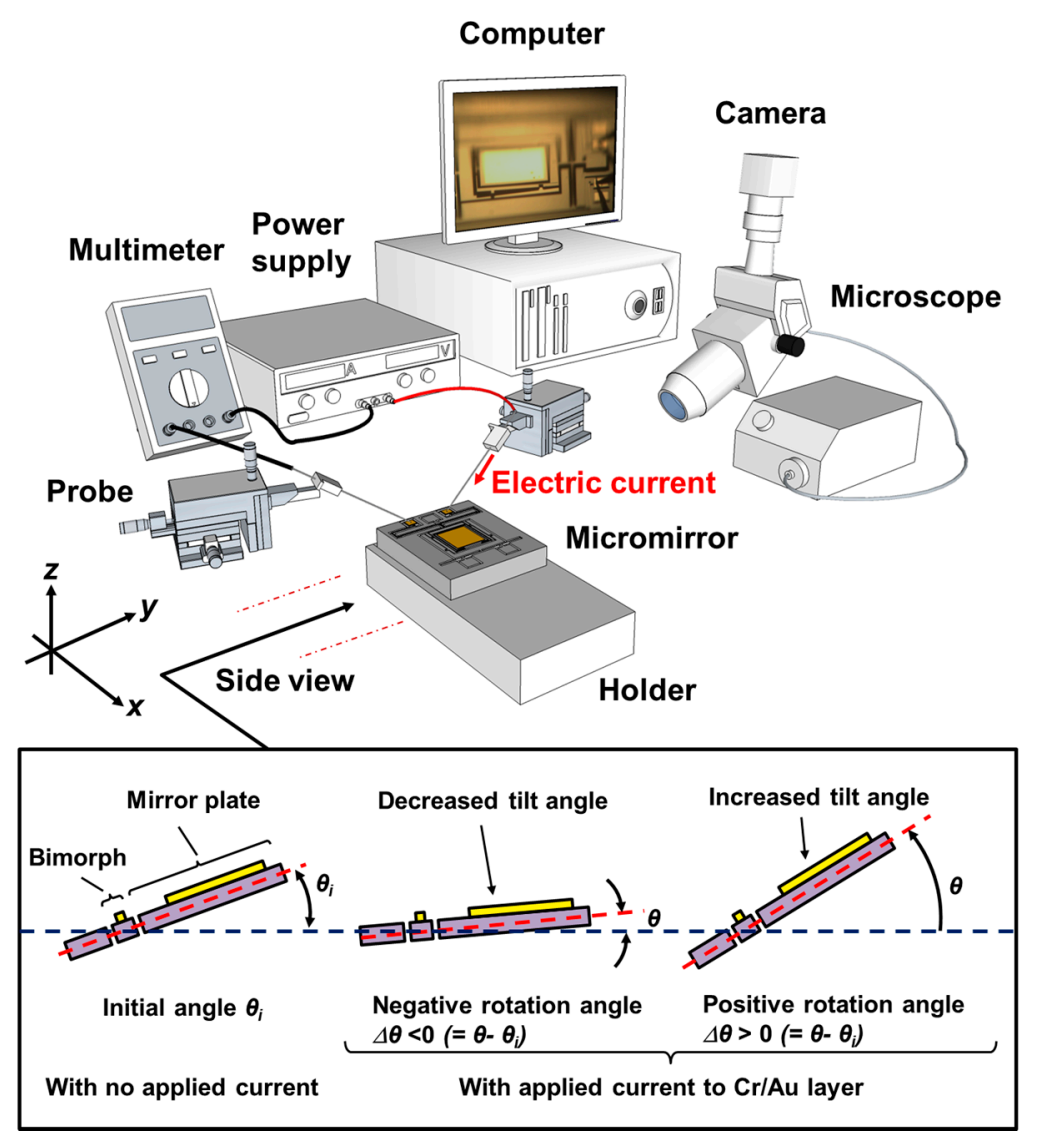

Figure 4. Experimental setup for measuring the rotation angle, corresponding voltage and electrical resistance of the MEMS mirror when an external electric current is applied.

Figure 5 shows the experimental results for the bending-type MEMS mirrors of different wire resistances. The total resistance including that between the current input and output pads and that of external wires and components is also measured. When the applied current increases, the resistance is substantially increased due to temperature rise. When applying the current, Joule heating raises the temperature of the bimorph actuator. Due to the thermal expansion coefficient mismatch, the increased temperature then results in a difference in deformation between the $\mathrm{Cr} / \mathrm{Au}$ layer and the underlying Si beam. In the experiment, the rotation angle $\Delta \theta$ of the mirror is defined as mentioned above shown in Figure 4. Figure 5a shows the optical microscope images taken at the applied currents of 0 and $0.04 \mathrm{~A}$. 
Figures $5 \mathrm{~b}$ shows the rotation angles of the mirrors $v s$. the applied current. Devices are measured at currents ranging from $0 \mathrm{~A}$ to $0.04 \mathrm{~A}$. As expected, the device reaches the largest absolute value of the rotation angle at $0.04 \mathrm{~A}$. With an applied current of $0.04 \mathrm{~A}$, it is $1.69^{\circ}$ and $1.35^{\circ}$ for the low- and high-resistance devices, respectively. The maximum power consumptions occur at $0.04 \mathrm{~A}$, and are 101 and $180 \mathrm{~mW}$, respectively. Figure 5c shows the relations of the applied voltage (i.e., voltage output from the power supply) vs. the applied current. The voltage increases with the applied current as expected. Figure $5 \mathrm{~d}$ shows the total resistance $v s$. the applied current. The resistance increases with the applied current as mentioned earlier.

(a)

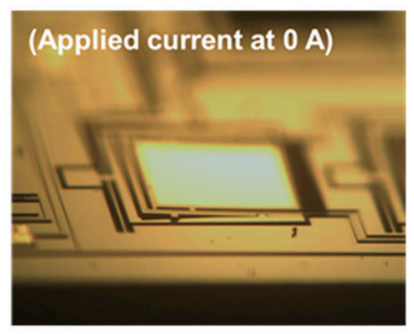

(c)
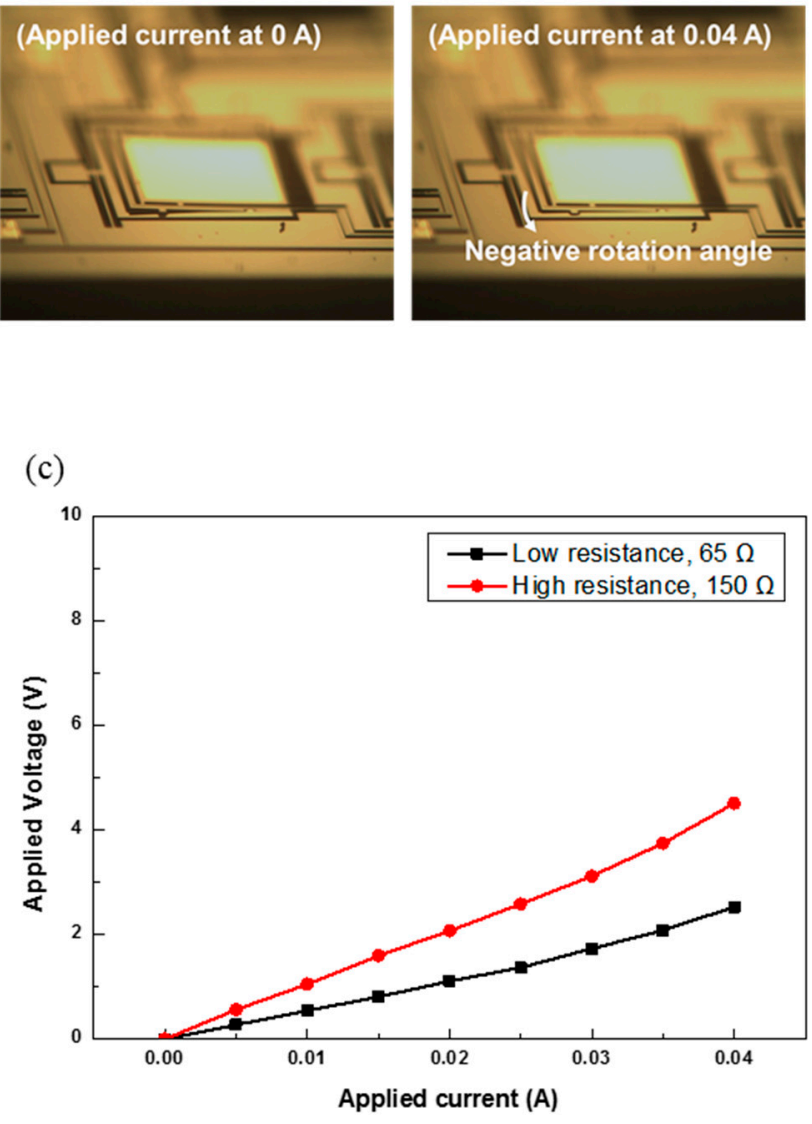

(b)

(d)
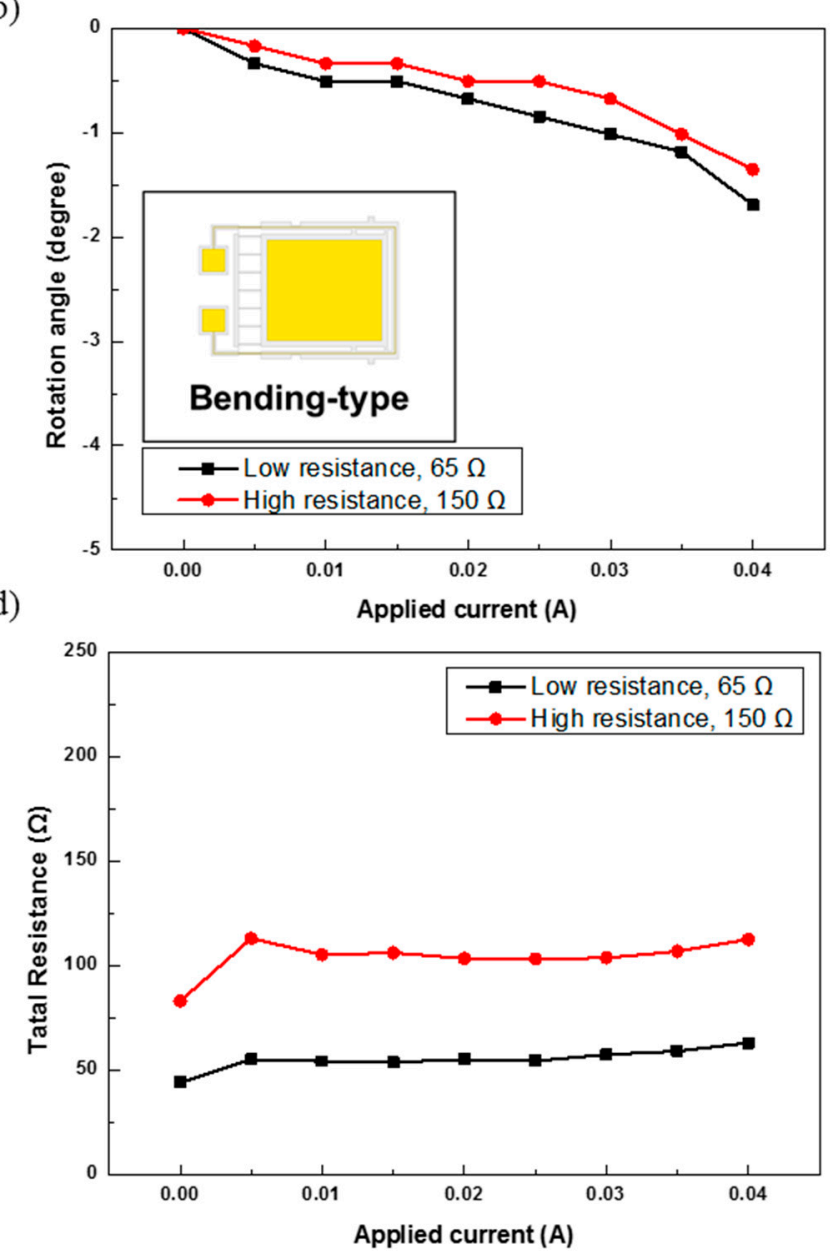

Figure 5. Experimental results for the bending-type MEMS mirrors of different wire resistances: (a) optical microscope images; (b) rotation angles; (c) applied voltages; and (d) total resistances.

Figure 6 shows the experimental results for the restricted-torsion-type MEMS mirrors of different wire resistances. Figure $6 \mathrm{a}$ shows the optical microscope images at 0 and 0.04 A. Figure $6 \mathrm{~b}$ shows the rotation angles of the mirrors vs. the applied current. At $0.04 \mathrm{~A}$, the absolute value of the rotation angle is $2.91^{\circ}$ and $3.28^{\circ}$ for the low- and high-resistance devices, respectively. The power consumption at $0.04 \mathrm{~A}$ is 123 and $316 \mathrm{~mW}$ for the low- and high-resistance mirror, respectively. Figure $6 \mathrm{c}, \mathrm{d}$ show the relations of the applied voltage and total resistance $v s$. the applied current. The applied voltage and total resistance both increase with the applied current. 
(a)
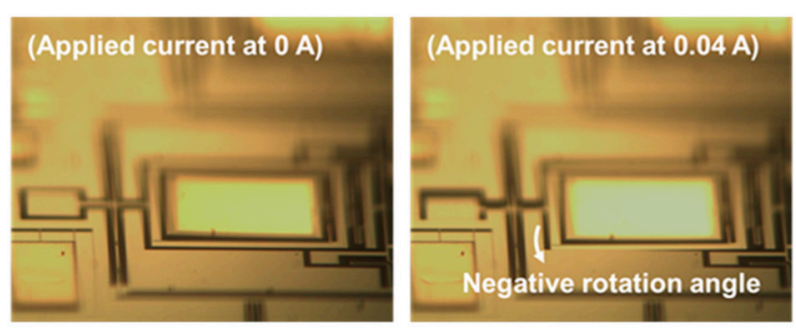

(c)

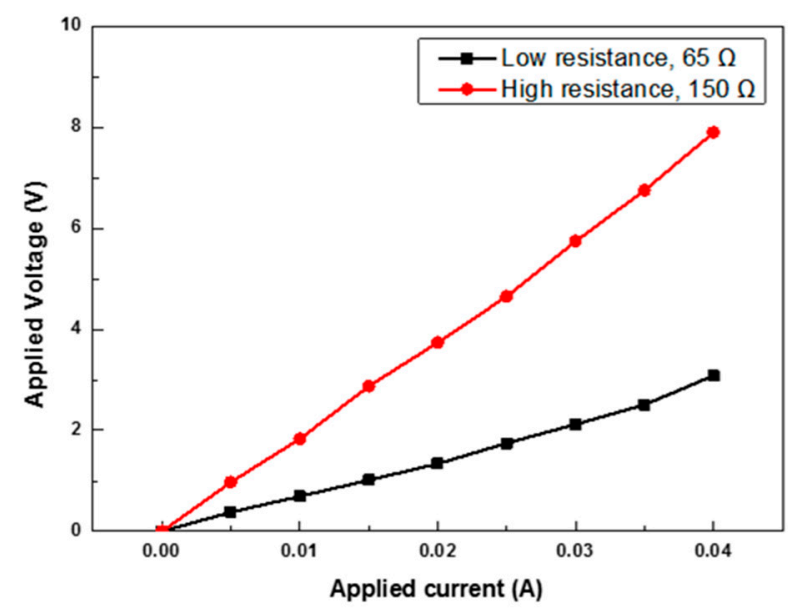

(b)

(d)
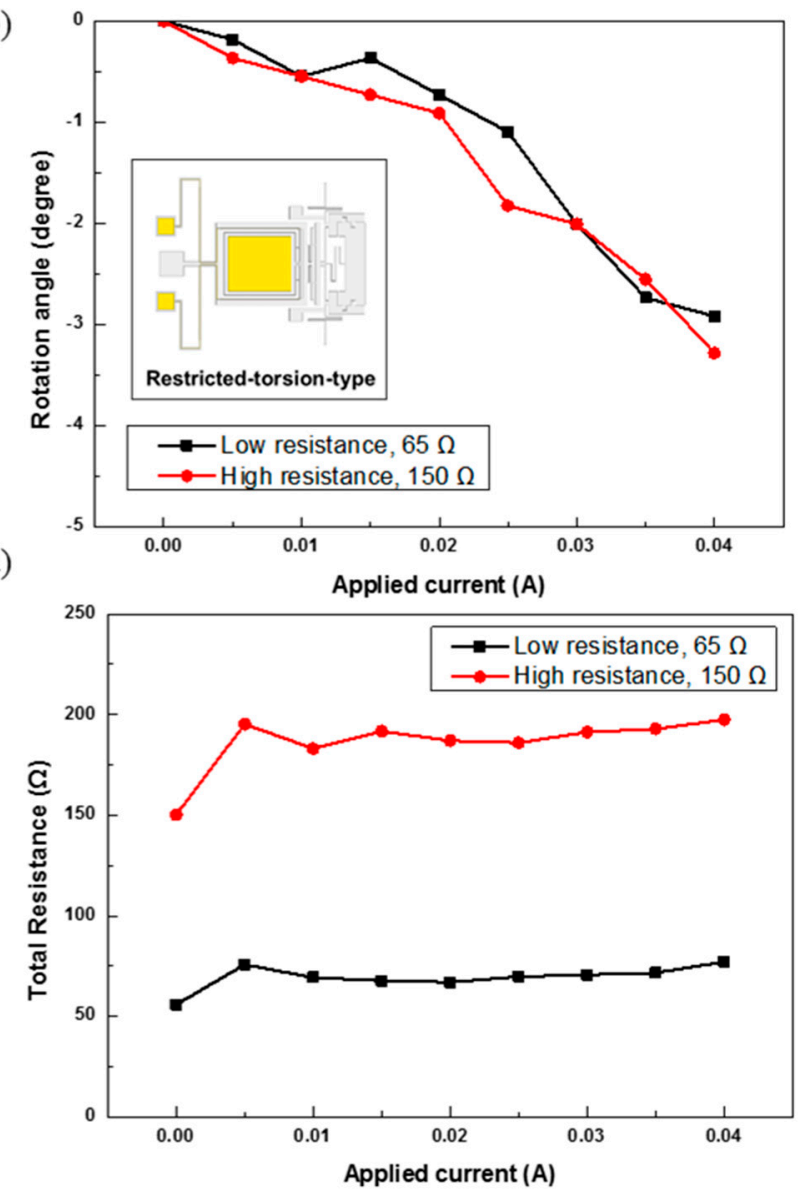

Figure 6. Experimental results for the restricted-torsion-type MEMS mirrors of different wire resistances: (a) optical microscope images; (b) rotation angles; (c) applied voltages; and (d) total resistances.

Figure 7 shows the experimental results for the free-torsion-type MEMS mirror of different wire resistances. Figure $7 \mathrm{a}$ shows the optical microscope image at 0 and $0.04 \mathrm{~A}$. Figure $7 \mathrm{~b}$ shows the rotation angles of the mirror $v s$. the applied current. The rotation angle at $0.04 \mathrm{~A}$ is $3.64^{\circ}$ and $3.28^{\circ}$ for the low- and high-resistance devices, respectively. The maximum power consumption occurs at $0.04 \mathrm{~A}$; it is 124 and $278 \mathrm{~mW}$ for the low-and high-resistance mirrors, respectively. Figure 7c,d show the relations of the applied voltage and total resistance vs. the applied current. The total voltage and resistance both increase with the applied current.

Figure 8 shows a schematic diagram of the experimental setup for measuring laser beam displacement. The beam steering capability of the mirror was verified by shining a HeNe laser beam on the mirror and tracing the light spot of the reflected beam on a screen. The applied current is increased from 0 to $0.04 \mathrm{~A}$ with an increment of $0.01 \mathrm{~A}$. Figure 9 shows the movement of the light spot and the mirror postures at $0 \mathrm{~A}$ and $0.04 \mathrm{~A}$. The shift of the light spot is clearly observed. 
(a)

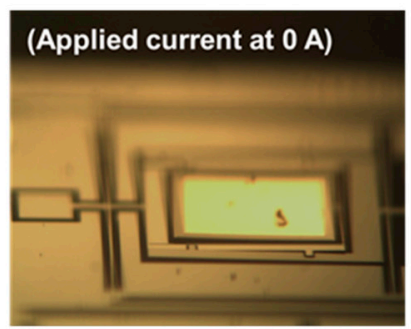

(c)
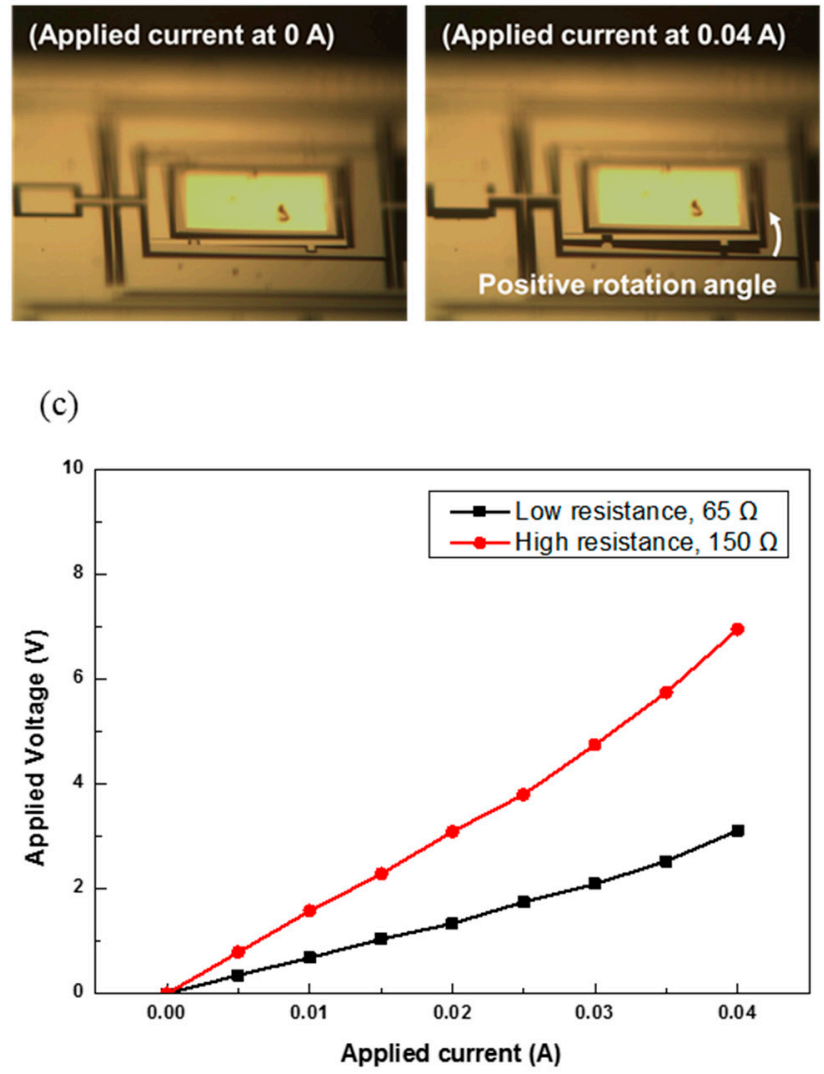

(b)

(d)
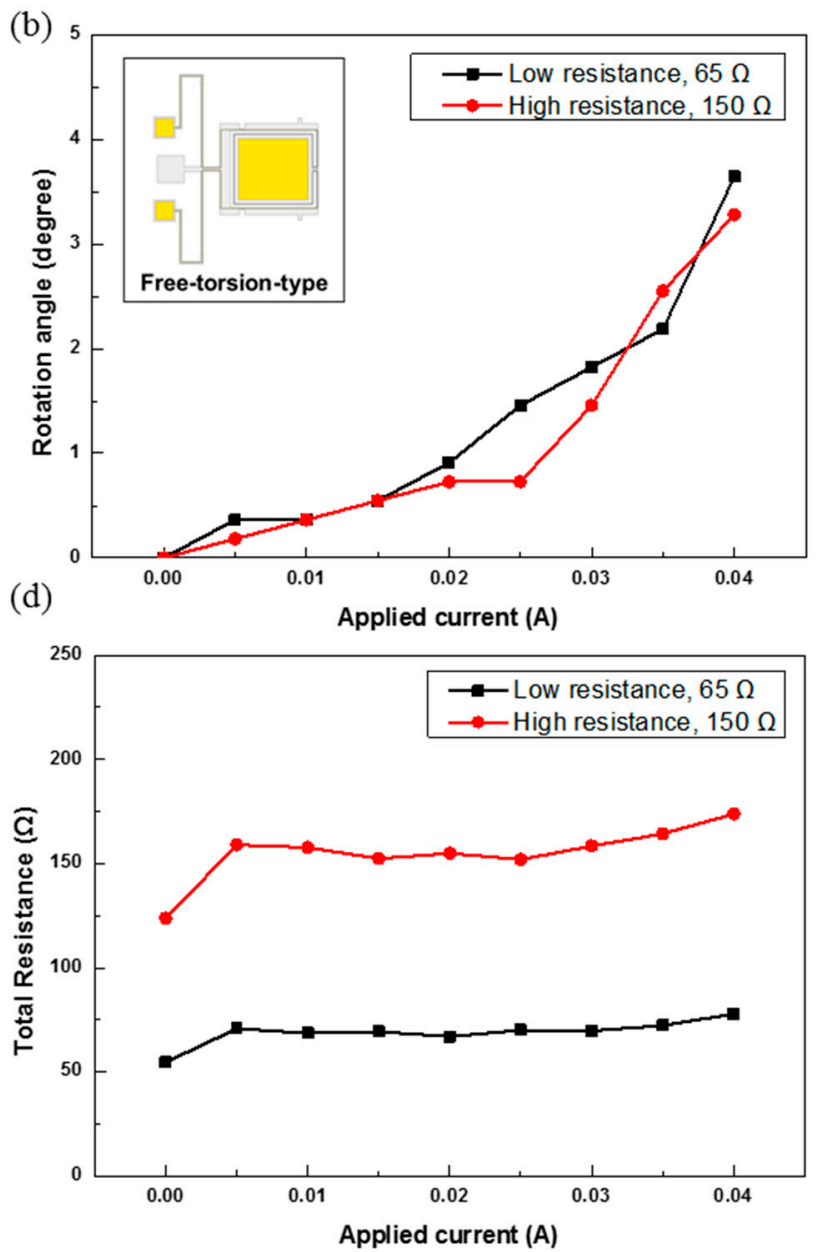

Figure 7. Experimental results for the free-torsion-type MEMS mirrors of different wire resistances: (a) optical microscope images; (b) rotation angles; (c) applied voltages; and (d) total resistances.

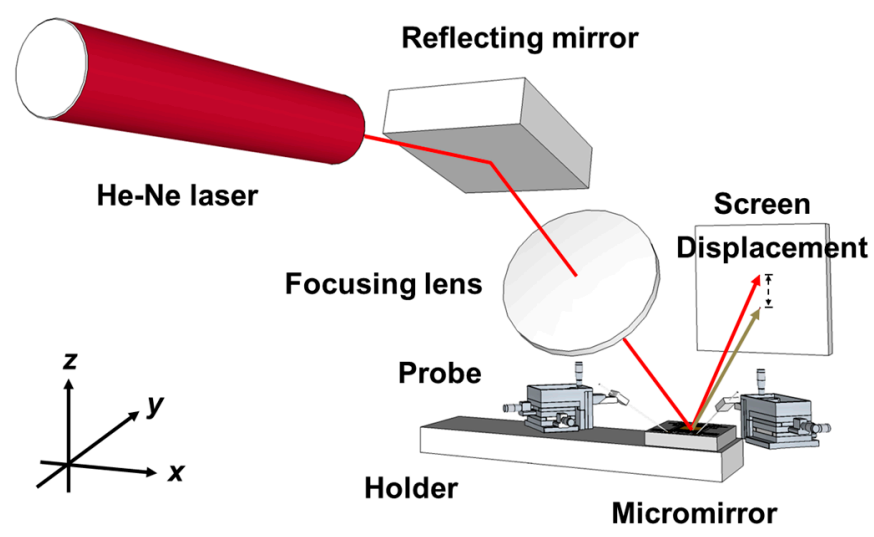

Figure 8. Schematic drawing of the experimental setup for tracing the light spot of the reflected laser beam. 

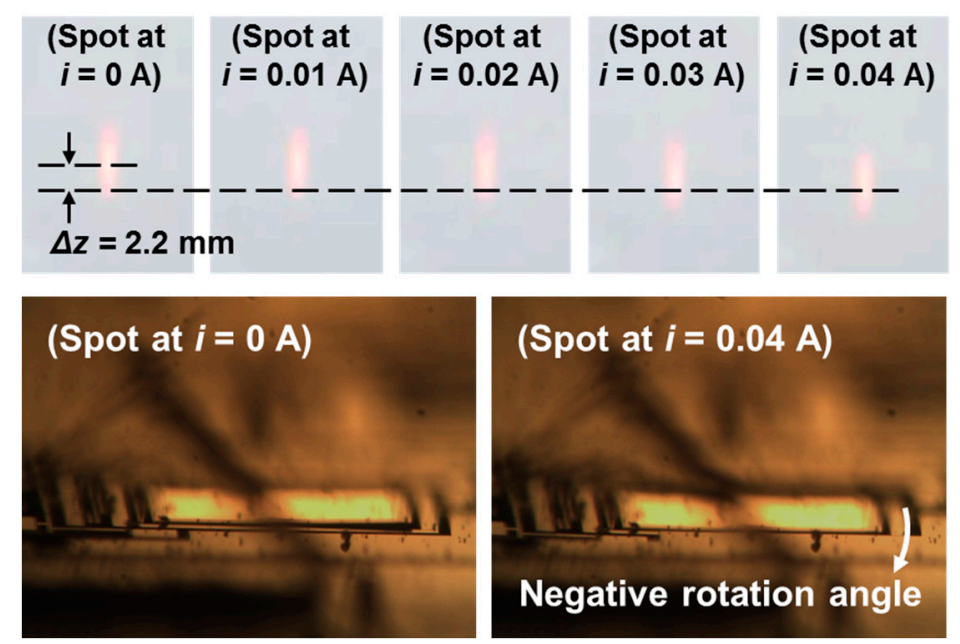

Figure 9. Trace of the light spot on a screen of the reflected laser beam from the restricted-torsion-type mirror. In addition, the mirror postures at $i=0 \mathrm{~A}$ and $0.04 \mathrm{~A}$ are shown.

\section{Discussion and Conclusions}

This study presents three different electrothermally actuated MEMS mirrors. A silicon-on-insulator MEMS process has been used for the fabrication of these micromirrors. In addition to a traditional bending structure, we also investigate the possibility of fabricating bimorph structures, which also serve as the torsion springs. At the maximum current of $0.04 \mathrm{~A}$, the bending-type mirror has the lowest power consumption compared to the other two types of devices. The free-torsion-type mirror has the largest rotation range. The restricted-torsion-type mirror and free-torsion-type mirror have lower resonance frequencies than the bending-type mirror.

These micromirrors, which are operated by electrothermal actuation, achieve decent angular movement. When an external electrical current of $0.04 \mathrm{~A}$ is applied, the bending-type, restricted-torsion-type, and free-torsion-type mirrors have rotation angles of $1.69^{\circ}, 3.28^{\circ}$, and $3.64^{\circ}$ (absolute values), respectively. It has been demonstrated that the devices can be fabricated with a simple fabrication process and work with a low driving voltage. They are potentially suitable for many optical applications.

\section{Acknowledgments}

This work was supported by the Ministry of Science and Technology of Taiwan under Grants NSC 100-2628-E-002-002 and NSC 101-2221-E-002-056-MY3, by Grant 104R3401-2 of National Taiwan University, and by Devices for Solar Energy, Light Sources, Display, and Sensing under Excellent Research Projects of National Taiwan University, Grant 10R80919-1, Grant AE01-01 (101R89081), Grant 102R89084, Grant NTU-ERP-103R89084, and Grant NTU-ERP-104R89084.

\section{Author Contributions}

Cheng-Hua Tsai and Chun-Wei Tsai designed the devices, performed the experiments, and analyzed the data. Hsu-Tang Chang and Shih-Hsiang Liu assisted in the preliminary device inspection and testing. Cheng-Hua Tsai wrote the paper. Jui-Che Tsai directed the research project. 


\section{Conflicts of Interest}

The authors declare no conflict of interest.

\section{References}

1. Wu, M.C.; Solgaard, O.; Ford, J.E. Optical MEMS for Lightwave Communication. J. Lightw. Technol. 2006, 24, 4433-4454.

2. Yano, M.; Yamagishi, F.; Tsuda, T. Optical MEMS for photonic switching-Compact and stable optical crossconnect switches for simple, fast, and flexible wavelength applications in recent photonic networks. IEEE J. Sel. Top. Quantum Electron. 2005, 11, 383-394.

3. Liao, C.; Tsai, J. The evolution of MEMS displays. IEEE Trans. Ind. Electron. 2009, 56, $1057-1065$.

4. Jung, W.; Zhang, J.; Wang, L.; Wilder-Smith, P.; Chen, Z.; McCormick, D.T.; Tien, N.C. Three-dimensional optical coherence tomography employing a 2-axis microelectromechanical scanning mirror. IEEE J. Sel. Top. Quantum Electron. 2005, 11, 806-810.

5. Bai, Y.; Yeow, J.T.W.; Constantinou, P.; Damaskinos, S.; Wilson, B.C. A 2-D micromachined SOI MEMS mirror with sidewall electrodes for biomedical imaging. IEEE/ASME Trans. Mechatron. 2010, 15, 501-510.

6. Wang, K.; Nirmalathas, A.; Lim, C.; Skafidas, E.; Alameh, K. High-speed reconfigurable free-space card-to-card optical interconnects. IEEE Photon. J. 2012, 4, 1407-1419.

7. Hu, F.; Yao, J.; Qiu, C.; Ren, H. A MEMS micromirror driven by electrostatic force. J. Electrostat. 2010, 68, 237-242.

8. Ma, Y.; Islam, S.; Pan, Y. Electrostatic torsional micromirror with enhanced tilting angle using active control methods. IEEE/ASME Trans. Mechatron. 2011, 16, 994-1001.

9. He, G.; Geng, Z. Finite-time stabilization of a comb-drive electrostatic microactuator. IEEE/ASME Trans. Mechatron. 2012, 17, 107-115.

10. Ji, C.; Choi, M.; Kim, S.; Song, K.; Bu, J.; Nam, H. Electromagnetic Two-Dimensional Scanner Using Radial Magnetic Field. J. Microelectromech. Syst. 2007, 16, 989-996.

11. Weber, N.; Hertkorn, D.; Zappe, H.; Seifert, A. Polymer/silicon hard magnetic micromirrors. J. Microelectromech. Syst. 2012, 21, 1098-1106.

12. Yalcinkaya, A.D.; Ergeneman, O.; Urey, H. Polymer magnetic scanners for bar code applications. Sens. Actuators A Phys. 2007, 135, 236-243.

13. Koh, K.H.; Kobayashi, T.; Lee, C. Low-voltage driven MEMS VOA using torsional attenuation mechanism based on piezoelectric beam actuators. IEEE Photon. Technol. Lett. 2010, 22, 1355-1357.

14. Jain, A.; Qu, H.; Todd, S.; Xie, H. A thermal bimorph micromirror with large bi-directional and vertical actuation. Sens. Actuators A Phys. 2005, 122, 9-15.

15. Jia, K.; Pal, S.; Xie, H. An electrothermal tip-tilt-piston micromirror based on folded dual S-shaped bimorphs. J. Microelectromech. Syst. 2009, 18, 1004-1015.

16. Liu, L.; Pal, S.; Xie, H. MEMS mirrors based on a curved concentric electrothermal actuator. Sens. Actuators A Phys. 2012, 188, 349-358. 
17. Liu, W.; Talghader, J.J. Spatial-mode analysis of micromachined optical cavities using electrothermal mirror actuation. J. Microelectromech. Syst. 2006, 15, 777-785.

18. Hanhijärvi, K.; Kassamakov, I.; Aaltonen, J.; Heikkinen, V.; Sainiemi, L.; Franssila, S.; Hæggström, E. Through-silicon stroboscopic characterization of an oscillating MEMS thermal actuator using supercontinuum interferometry. IEEE/ASME Trans. Mechatron. 2013, 18, 1418-1420.

19. Xu, Y.; Singh, J.; Chen, N. Large rotation angle micromirror based on hypocycloidal electrothermal actuators. Electron. Lett. 2010, 46, 704-706.

20. Kim, D.H.; Park, Y.C.; Park, S. Design and fabrication of twisting-type thermal actuation mechanism for micromirrors. Sens. Actuators A Phys. 2010, 159, 79-87.

21. Pal, S.; Xie, H. Pre-shaped open loop drive of electrothermal micromirror by continuous and pulse width modulated waveforms. IEEE J. Quantum Electron. 2010, 46, 1254-1260.

22. Xu, Y.; Singh, J.; Selvaratnam, T.; Chen, N. Two-axis gimbal-less electrothermal micromirror for large-angle circumferential scanning. IEEE J. Sel. Top. Quantum Electron. 2009, 15, 1432-1438.

23. Wu, L.; Xie, H. Electrothermal micromirror with dual-reflective surfaces for circumferential scanning endoscopic imaging. J. Micro/Nanolithogr. MEMS MOEMS 2009, 8, 013030.

24. Li, L.; Li, R.; Lubeigt, W.; Uttamchandani, D. Design, simulation, and characterization of a bimorph varifocal micromirror and its application in an optical imaging system. IEEE J. Microelectromech. Syst. 2013, 22, 285-294.

25. Li, L.; Bauer, R.; Brown, G.; Uttamchandani, D. A 2D MEMS scanning micromirror with electrothermal and electrostatic actuators. In Proceeding of the IEEE International Conference on Optical MEMS and Nanophotonics (OMN 2012), Banff, AB, Canada, 6-9 August 2012; pp. 73-74.

26. Li, L.; Bauer, R.; Brown, G.; Uttamchandani, D. A symmetric hybrid MEMS scanner with electrothermal and electrostatic actuators. In Proceeding of the IEEE International Conference on Optical MEMS and Nanophotonics (OMN 2011), Istanbul, Turkey, 8-11 August 2011; pp. 163-164.

27. Wu, L.; Xie, H. $124^{\circ}$ rotation angle electrothermal micromirror with integrated platinum heater. IEEE J. Sel. Top. Quantum Electron. 2007, 13, 316-321.

28. Puchades, I.; Fuller, L.F. A thermal actuated microelectromechanical (MEMS) device for measuring viscosity. J. Microelectromech. Syst. 2011, 20, 601-608.

29. Dean, J.A. Lange's Handbook of Chemistry, 15th ed.; McGraw-Hill, Inc.: Knoxville, TN, USA, 1999.

30. Cowen, A.; Hames, G.; Monk, D.; Wilcenski, S.; Hardy, B. SOIMUMPs Desigh Handbook, Rev. 8.0; MEMSCAP, Inc.; Durham, NC, USA, 2002.

(C) 2015 by the authors; licensee MDPI, Basel, Switzerland. This article is an open access article distributed under the terms and conditions of the Creative Commons Attribution license (http://creativecommons.org/licenses/by/4.0/). 